\title{
Determinants of Workers' Remittances: Turkish Evidence from High-Frequency Data
}

\section{Ahmet Murat Alper \& Bilin Neyapti}

To cite this article: Ahmet Murat Alper \& Bilin Neyapti (2006) Determinants of Workers'

Remittances: Turkish Evidence from High-Frequency Data, Eastern European Economics, 44:5, $91-100$

To link to this article: http://dx.doi.org/10.2753/EEE0012-8775440504

册Published online: 08 Dec 2014.

Submit your article to this journal

Џ Article views: 16

Q View related articles $\asymp$

4 Citing articles: 8 View citing articles 
Eastern European Economics, vol. 44, no. 5, September-October 2006, pp. 91-100.

(C) 2006 M.E. Sharpe, Inc. All rights reserved.

ISSN 0012-8775/2006 \$9.50+0.00.

DOI 10.2753/EEE0012-8775440504

\title{
AHMET MURAT ALPER AND BILIN NEYAPTI
}

\section{Determinants of Workers' Remittances}

\author{
Turkish Evidence from High-Frequency Data
}

\begin{abstract}
The potential importance of workers remittances (WR) as a relatively stable source of foreign exchange has been growing across the world. We present time-series evidence on the determinants of WR in a large developing country, Turkey. Using yearly data, Aydas et al. (2005) show that WR flows to Turkey are significantly influenced by the growth rate of the home gross domestic product (GDP); the level of GDP in both home and host countries; interest rate differentials between home and host countries; the black market exchange rate; inflation; and political stability. This study utilizes higher-frequency data to further investigate the issue from both long-term and short-term perspectives. The new evidence supports the earlier findings regarding the long-run investment motive, but it also shows that consumption smoothing is an effective short-run motive for sending remittances to Turkey.
\end{abstract}

Neyapti (2004) argues that worker remittance (WR) flows can significantly influence the economies of only a handful of countries in the world, most of which are very small and open economies. ${ }^{1}$ Aydas et al. (2005) and Alper (2005) present recent surveys of the studies that analyze the various motives and determinants of WR. According to these studies, flows of WR that result in either consumption smoothing or investment can be attributed to deeper motives of altruism or selfinterest, or may be due to mutually beneficial agreements (see, e.g., Lucas and Stark 1985).

Earlier studies have indicated that the stock of migrant workers, the host country income, and the stability of the home country income, measured by economic and natural crises, inflation, and exchange rate stability, are among the macroeco-

Ahmet Murat Alper is an expert at the Central Bank of Turkey. Bilin Neyapti is associate professor in the Department of Economics of Bilkent University, Ankara, Turkey. The views herein are those of the authors and do not necessarily reflect the views of the Central Bank of Turkey. 
nomic determinants of WR (see Alper 2005 for a detailed survey). However, notwithstanding the difficulties in obtaining a healthy stock of data on WR from formal channels, the empirical evidence on the determinants of WR flows has been rather mixed across countries (for a detailed summary of the literature, see Alper 2005; Aydas et al. 2005). Nonetheless, recent studies indicate that WR appears to be a more reliable source of foreign exchange than do other alternatives, and thus, policies to encourage WR become increasingly important (see Neyapti 2004; Ratha 2003). Investigating the determinants of WR in a large developing country such as Turkey has significant implications for developing countries in general as the world continues to globalize.

This paper provides a time-series analysis of the determinants of WR in Turkey, using monthly data from January 1992 to December 2003. The study differs from two earlier investigations, Aydas et al. (2005) and Straubhaar (1986), both in terms of the frequency of data, which now enables a thorough time-series analysis, and in terms of the time period covered. The new evidence indicates that the investment motive is prevalent in the long run, but consumption smoothing is also observed in the short run. ${ }^{2}$

\section{Data and Methodology}

Aydas et al. (2005) and Straubhaar (1986) both analyze WR flows to Turkey. The first study looks at the annual data between 1963 and 1982 and concludes that interest and exchange rate policies did not affect WR flows to Turkey, whereas the number of workers abroad and real incomes of the migrant workers did. Aydas et al. (2005) confirm the results of Straubhaar (1986) for the significant effects, but also report the significant response of WR to interest and exchange rates for the period 1965-93; in other words, Aydas et al. (2005) point out that macroeconomic policy and stability matter to WR flows. In addition, Aydas et al. (2005) report that both consumption smoothing and investment motives are prevalent for the period 1979-2003, whereas only the consumption motive was observed for the period 1965-93. They argue that this is due to the closer links to the home country in the earlier years.

We felt the urge to revise the analysis reported in Aydas et al. (2005), due to the higher-frequency series that were recently made available by central bank sources. Using this additional time-series information, this paper provides a more thorough time-series analysis than do the earlier studies, ${ }^{3}$ though the period chosen is also complementary to the earlier studies.

We model WR following Aydas et al. (2005), in which WR flow is a function of the one-year Turkish lira deposit rate $(I N T)$; the consumer price index $(P)$; the exchange rate $(E R)$ of the lira to the euro; and the manufacturing production index $(I N C)$, which is used to measure home income level, as GDP is not available on a monthly basis. ${ }^{4}$ All of the data except for INT are used in logarithms. The monthly data cover the period between January 1992 and December 2003. 
Table 1

\section{Unit Root Test Results}

\begin{tabular}{llc} 
Variables & Constant & Constant and trend \\
\hline$W R$ & $-2.511(1)$ & $-2.580(1)$ \\
$I N T$ & $-1.269(1)$ & $-2.469(1)$ \\
$P$ & $-3.221(5)$ & $1.299(5)$ \\
$E R$ & $-1.888(1)$ & $-1.461(1)$ \\
$I N C$ & $-1.252(4)$ & $-2.388(5)$ \\
$d W R$ & $-10.957(1)^{\star}$ & $-10.943(1)^{\star}$ \\
$d I N T$ & $-8.523(0)^{*}$ & $-8.595(0)^{\star}$ \\
$d P$ & $-3.243(4)^{\star *}$ & $-4.719(4)^{\star}$ \\
$d E R$ & $-7.585(0)^{\star}$ & $-7.818(0)^{\star}$ \\
$d I N C$ & $-7.3778(4)^{\star}$ & $-7.351(4)^{\star}$ \\
Critical values & & \\
1 percent & -3.481 & -4.030 \\
5 percent & -2.884 & -3.444
\end{tabular}

Notes: Critical values are from MacKinnon (1991). * and ** imply the rejection of the null hypothesis at 1 percent and 5 percent critical values, respectively. The values in (.) are optimal lag lengths. $d X$ refers to first difference of variable $X$ (i.e., $\mathrm{d} X=X-X_{-1}$ ).

Our analysis consists of three steps. The first checks the stationarity of the series using the augmented Dickey-Fuller (ADF) unit test, as suggested by Dickey and Fuller $(1979 ; 1981)$. The second uses the multivariate cointegration technique developed by Johansen (1988) and Johansen and Juselius (1990) to test for a longrun relationship. The final step estimates a vector error correction model (VECM) to capture the short-run dynamic adjustment of the cointegrated variables.

\section{Empirical Evidence}

To analyze the relationship between WR and its hypothesized determinants, we first perform unit root tests. Table 1 reports the ADF tests, performed both with a constant term (column 1) and with a constant and a trend term (column 2). We used seasonal dummies to estimate WR and INC, and used Schwartz criteria to determine the lag lengths in all variables. In the case of serial correlation, a sufficient number of $\operatorname{lag}(\mathrm{s})$ is introduced to eliminate serial correlation. In Table 1, we observe that WR, INT, ER, INC, and $P$ are all stationary after taking first differences, both with a constant term and with a constant and a trend term. 
Upon finding that all of the variables are stationary after first differences, we note that cointegration of WR with interest rate, price level, exchange rate, and income is a necessary condition for the existence of a long-run relationship among them. Using the stationary series, we first investigate the appropriate lag lengths in the VECM, based on Akaike and Schwartz criteria, in addition to performing the various diagnostic tests. ${ }^{5}$ This process suggests that a lag length of eight is optimal and produces a serially uncorrelated error term. We use a set of monthly centered seasonal dummy variables to capture the effects of seasonality on the variables, and two impulse dummy variables for November 2000 and February 2001, which are the crises periods. ${ }^{6}$

Panel I in Table 2 represents the estimates of the Johansen procedure and standard statistics. Trace and maximum eigenvalue test statistics, together with the 1 percent critical value, indicate the existence of a single cointegration vector. Panel II in Table 2 reports standardized eigenvectors $\beta^{\prime}$. The first row of $\beta^{\prime}$ is the estimated cointegration vector, and can be written in an equation form as follows:

$$
W R=-9.297+0.003 I N T-0.736 P+0.702 E R+2.132 I N C .
$$

Based on the long-run relationship, though the interest, income, and exchange rates are positively related to remittance flows, prices are negatively related. Hence, the estimated signs support the presence of the investment motive in sending remittances to Turkey. The error correction term depicted in Figure 1 also confirms that the cointegrating vector is stationary.

Panel III in Table 2 reports the estimated response of each of the variables to the error correction term, $\alpha$. The rates of response are very slow. The first term in $\alpha$ shows that WRs have a feedback coefficient of -0.04 , which implies that the 4 percent of the adjustment is achieved in the first month.

Panel IV in Table 2 reports the weak exogeneity test statistics. The test results show that WR and income are weakly exogenous, at 5 percent and 1 percent significance levels, respectively. The evidence is consistent with the fact that the interest rate, price levels, and the exchange rate are mainly determined outside the system.

Finally, Panel V in Table 2 reports the values of multivariate statistics for testing the stationarity of a given variable. We reject the null hypothesis of multivariate stationarity of all the variables, except for $W R$ at 1 percent level.

Based on the cointegration and weak exogeneity test results, the next step is to map VECM corresponding to the cointegrating vector with constant and dummy variables. Following a general-to-specific simplification procedure, we estimate the VECM using the seemingly unrelated regression (SUR) method, and eliminate negligible and insignificant effects through a sequential reduction process suggested by Hendry (1995). The final restricted estimates of the VECM are summarized in Table 3.

The significance of the error correction term provides evidence that the estimated model is statistically sound. Furthermore, Table 3 shows that the short-run 


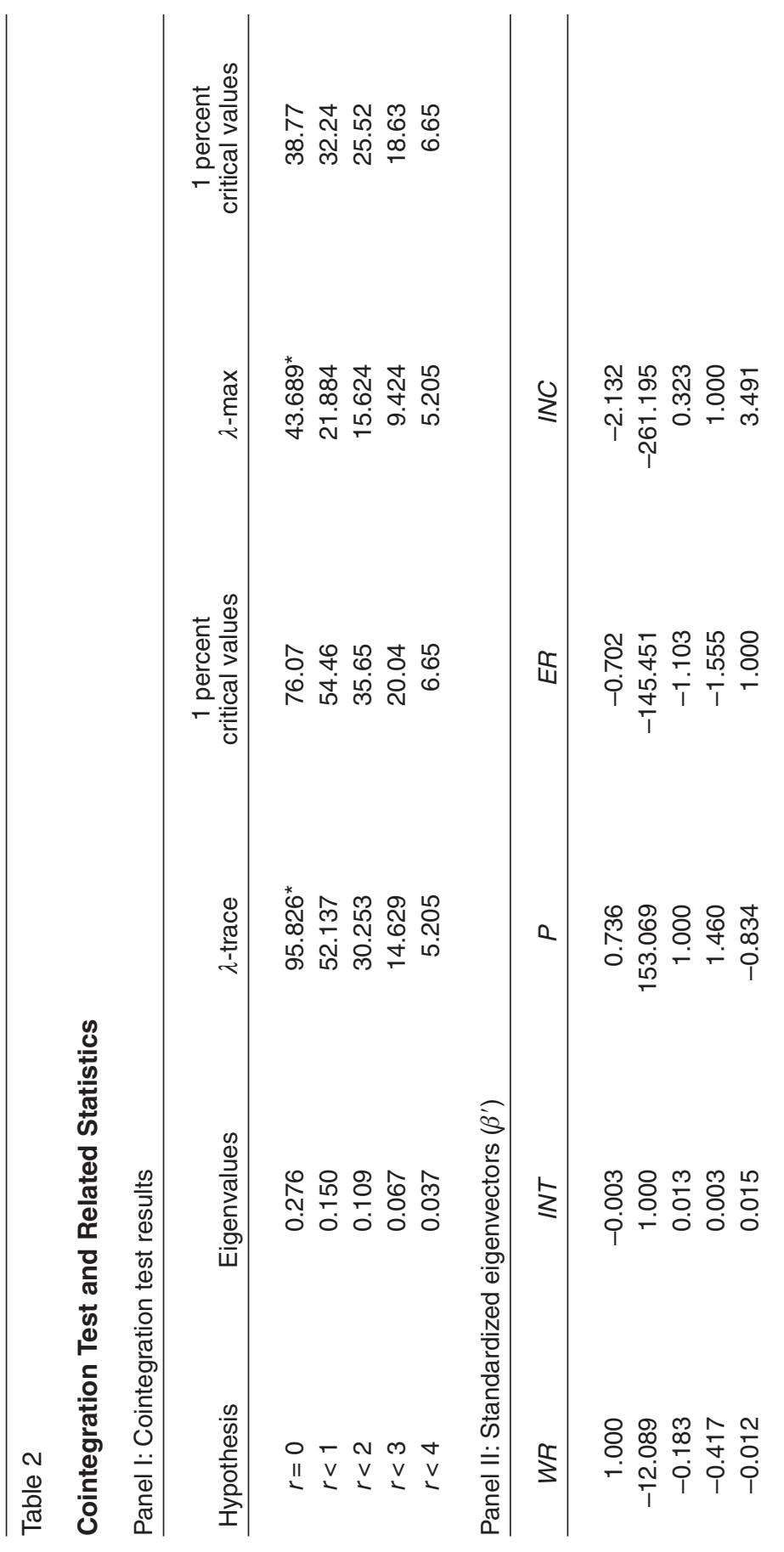


96

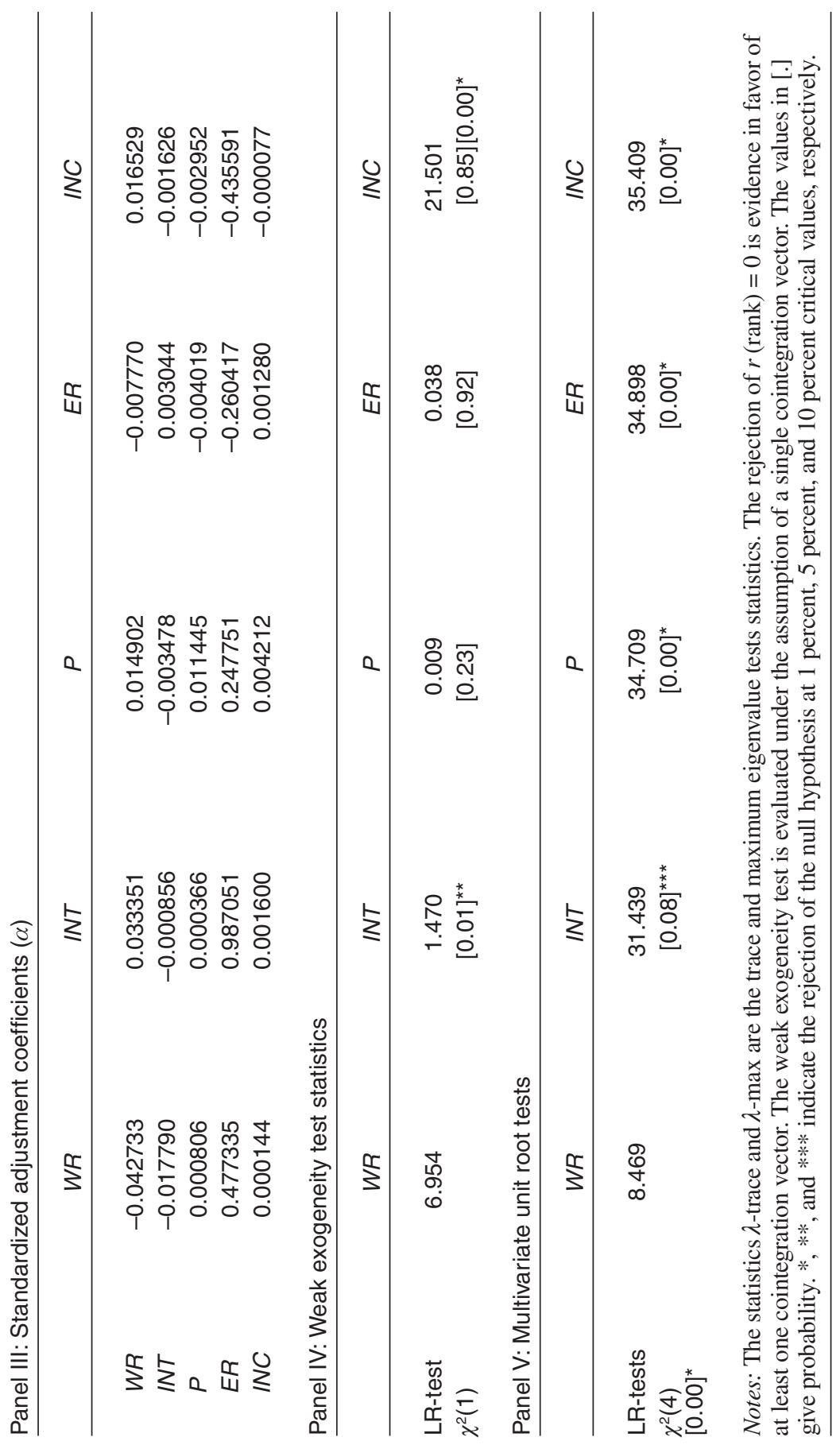


Figure 1. Error Correction Term

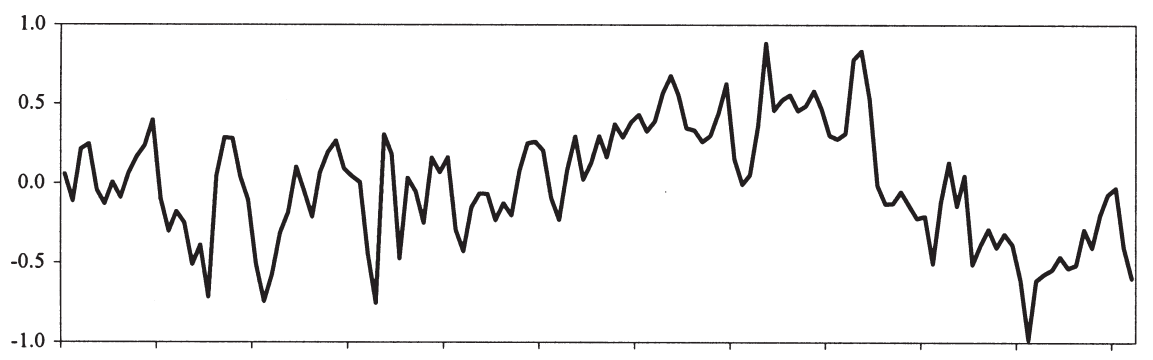

dynamics of the determinants of $W R$ exhibit a contrasting view compared to the long term: The investment motive prevails in the long run, but the consumptionsmoothing motive dominates the short run. The sums of the significant coefficients of the lagged terms of INT, ER, and INC are negative, and the sum of the significant coefficients of the lagged terms of $P$ is positive in the short run.

\section{Conclusion}

This study investigates the determinants of WR to Turkey using monthly data between January 1992 and December 2003. The time-series evidence indicates that, in the long run, favorable domestic conditions, such as low inflation, high income, interest rates, and exchange rates ${ }^{7}$ are all inducing more remittance flows to Turkey, whereas high inflation reduces such flows. This finding indicates that the investment motive dominates long-run remittance flows. By contrast, the shortrun or temporary flows are induced by the reverse circumstances, indicating that the consumption-smoothing motive dominates short-run remittance flows. The findings not only confirm those of Aydas et al. (2005) in a different time frame, but are also stronger due to its time-series methodology.

The current study carries important policy advice for developing countries. Considering that investment is a strong long-run motive for remittance flows, favorable economic conditions not only help to strengthen domestic economic activity, but also help to attract remittance flows that appear to provide more stable foreign exchange flows to developing countries than other sources worldwide.

\section{Notes}

1. Lebanon, Samoa, Eritrea, Republic of Yemen, Jordan, Cape Verde, Tonga, Albania, and El Salvador are the only countries that received WR flows of more than 10 percent of the respective GDPs during the 1990s (Neyapti 2004).

2. We argue that consumption smoothing can be inferred by the negative response of WR flows to income, whereas investment motive is revealed by the positive response of WR flows to income. 
Table 3

\section{SUR Estimates of Workers' Remittances Equation}

\begin{tabular}{|c|c|c|c|}
\hline Variable & Coefficient & $t$-statistics & Probability \\
\hline C & -0.119 & -2.719 & 0.01 \\
\hline$E C_{t-1}$ & -0.228 & -5.475 & 0.00 \\
\hline$d W R_{t-1}$ & -0.227 & -2.876 & 0.00 \\
\hline$d W R_{t-3}$ & 0.219 & 2.907 & 0.00 \\
\hline$d W R_{t-5}$ & -0.146 & -2.043 & 0.04 \\
\hline$d I N T_{t-3}$ & -0.010 & -3.028 & 0.00 \\
\hline$d I N T_{t-4}$ & -0.007 & -2.473 & 0.01 \\
\hline$d I N T_{t-7}$ & -0.006 & -2.163 & 0.03 \\
\hline$d P_{t}$ & 3.308 & 3.958 & 0.00 \\
\hline$d P_{t-1}$ & 2.109 & 2.449 & 0.02 \\
\hline$d P_{t-5}$ & 3.242 & 3.116 & 0.00 \\
\hline$d P_{t-6}$ & -2.397 & -2.857 & 0.00 \\
\hline$d P_{t-8}$ & 1.202 & -1.715 & 0.09 \\
\hline$d E R_{t-1}$ & -1.007 & -3.148 & 0.00 \\
\hline$d E R_{t-5}$ & -1.356 & -4.087 & 0.01 \\
\hline$d I N C_{t-1}$ & -0.671 & -2.660 & 0.01 \\
\hline$d I N C_{t-3}$ & -0.626 & -2.477 & 0.01 \\
\hline$d I N C_{t-4}$ & -0.659 & -2.444 & 0.02 \\
\hline$d I N C_{t-5}$ & -0.974 & -3.602 & 0.00 \\
\hline$d I N C_{t-6}$ & -0.486 & -1.888 & 0.06 \\
\hline S01 & -0.149 & -2.403 & 0.02 \\
\hline So2 & -0.390 & -5.147 & 0.00 \\
\hline SO3 & -0.248 & -3.222 & 0.00 \\
\hline SO4 & -0.160 & -2.056 & 0.04 \\
\hline 509 & -0.153 & -2.150 & 0.03 \\
\hline$S 10$ & -0.289 & -4.283 & 0.00 \\
\hline$S 11$ & -0.241 & -3.579 & 0.00 \\
\hline$D 00$ & 0.369 & 2.249 & 0.03 \\
\hline
\end{tabular}

Notes: $t-i$ shows the number of lags. $C$ is constant term, $E C$ is error correction term, $S$ is monthly centered seasonal dummy variable, and $D O O$ is dummy variable for November 2000 .

3. Even though the current data and methodology are an advance over previous studies, we concede that the power of time-series tests is still small, due to the coverage of only twelve years of data.

4. All the data are obtained from the electronic delivery system of the Central Bank of Turkish Republic. 
5. While we find five lags based on the Akaike criteria and one lag based on the Schwartz criteria, we choose to use eight lags to eliminate the serial correlation (see Appendix Table A1). Despite the violation of the normality assumption, we proceed with the Johansen test because it does not suffer from this problem (Gonzalo 1994).

6. We also tried to use a dummy for the 1994 crises. However, we dropped it because it causes serial correlation.

7. As Turkey is a net exporter to the euro area, a high lira-to-euro exchange rate indicates greater competitiveness for Turkey regarding European trade.

\section{References}

Alper, A.M. 2005. "İsci Dovizleri Belirleyen Makro Ekonomik Etkenler: Turkiye Ornegi" [Macroeconomic Determinants of Worker Remittances]. Expert Thesis, Central Bank of Turkish Republic, Ankara.

Aydas, O.T.; B. Neyapti; and K. Metin-Ozcan. 2005. "Determinants of Workers Remittances: The Case of Turkey." Emerging Markets Finance and Trade 41, no. 3 (MayJune): $53-69$.

Dickey, D.A., and W.A. Fuller. 1979. "Distribution of the Estimators for Autoregressive Time Series with a Unit Root." Journal of the American Statistical Association 74, no. 366: 427-431.

- 1981. "Likelihood Ratio Statistics for Autoregressive Time Series with a Unit Root." Econometrica 49, no. 4: 1057-1072.

Gonzalo, J. 1994. "Five Alternative Methods of Estimating Long-Run Equilibrium Relationships." Journal of Econometrics 60, nos. 1-2: 203-233.

Hendry, D.F. 1995. Dynamics Econometrics. Oxford: Oxford University Press.

Johansen, S. 1988. "Statistical Analysis of Cointegrating Vectors." Journal of Economic Dynamics and Control 12, nos. 2-3: 231-254.

Johansen, S., and K. Juselius. 1990. "Maximum Likelihood Estimation and Inference on Cointegration with Applications to the Demand for Money." Oxford Bulletin of Economics and Statistics 52 (May): 169-209.

Lucas, R.E.B., and O. Stark. 1985. "Motivations to Remit: Evidence from Botswana." Journal of Political Economy 93, no. 5: 901-918.

MacKinnon, J.G. 1991. "Critical Values for Cointegration Tests.” In Long-Run Economic Relationships, ed. R.F. Engle and C. Granger, pp. 267-276. Oxford: Oxford University Press.

Neyapti, B. 2004. "Trends in Workers Remittances: A World-Wide Overview.” Emerging Markets Finance and Trade 40, no. 2 (March-April): 83-90.

Ratha, D. 2003. "Worker Remittances: An Important and Stable Source of Development Finance." In Global Development Finance, Volume 1: Analysis and Statistical Appendix, pp. 157-175. Washington, DC: World Bank.

Straubhaar, T. 1986. "The Determinants of Workers' Remittances: The Case of Turkey." Weltwirtschafliches Archiv 122, no. 4: 728-740.

To order reprints, call 1-800-352-2210; outside the United States, call 717-632-3535. 
100 EASTERN EUROPEAN ECONOMICS

Appendix Table A1

\section{Diagnostic Tests of VECM}

Serial correlation LM test

\begin{tabular}{|c|c|c|}
\hline Lags & LM statistics & Probability \\
\hline 1 & 28.604 & 0.28 \\
\hline 2 & 29.918 & 0.23 \\
\hline 3 & 24.691 & 0.48 \\
\hline 4 & 21.259 & 0.68 \\
\hline 5 & 28.655 & 0.28 \\
\hline 6 & 17.876 & 0.85 \\
\hline 7 & 24.409 & 0.50 \\
\hline 8 & 30.067 & 0.22 \\
\hline 9 & 20.288 & 0.73 \\
\hline 10 & 22.634 & 0.60 \\
\hline 11 & 24.158 & 0.51 \\
\hline 12 & 34.054 & 0.11 \\
\hline \multicolumn{3}{|c|}{ White heteroskedasticity test } \\
\hline $\begin{array}{c}\chi^{2} \text { statistics } \\
1393.0\end{array}$ & $\begin{array}{c}\text { Probability } \\
0.72\end{array}$ & \\
\hline \multicolumn{3}{|c|}{ Jarque-Bera normality test } \\
\hline $\begin{array}{c}\chi^{2} \text { statistics } \\
69.705\end{array}$ & $\begin{array}{c}\text { Probability } \\
0.00\end{array}$ & \\
\hline
\end{tabular}

